\title{
Risks to healthcare workers following tracheal intubation of patients with known or suspected COVID-19 in Canada: data from the intubateCOVID registry
}

\author{
Matteo Parotto, MD on behalf of the intubateCOVID Canadian collaborators (1) Francesco Cavallin, MSc • \\ Gregory L. Bryson, MD on behalf of the intubateCOVID Canadian collaborators $\cdot$ Ki Jinn Chin, MD \\ on behalf of the intubateCOVID Canadian collaborators and the intubateCOVID International Coordinating \\ Centre
}

Received: 1 December 2020/Revised: 5 December 2020/Accepted: 6 December 2020/Published online: 11 January 2021

(C) Canadian Anesthesiologists' Society 2021

\section{To the Editor,}

Airway management may expose healthcare workers (HCWs) to the risk of contracting coronavirus disease (COVID-19). ${ }^{1}$ This exposure may occur in a broad range of clinical scenarios, from intubation of asymptomatic individuals undergoing elective surgery to emergent airway management for COVID-19-related respiratory failure. While efforts have been made to assess the magnitude of this risk, definitive data are lacking, and variability may exist across different settings and countries.

A prospective, international, quality improvement project (intubateCOVID; https://www.intubatecovid.org/ info) was launched to collect information on HCWs involved in tracheal intubation of patients with suspected or confirmed COVID-19. ${ }^{2}$ A waiver of formal research ethics approval was obtained from the Ottawa Health Science Network Research Ethics Board on 31 March

Supplementary Information The online version of this article (https://doi.org/10.1007/s12630-020-01890-3) contains supplementary material, which is available to authorized users.

M. Parotto, MD ( $\square)$

Department of Anesthesiology and Pain Medicine, University of

Toronto, Toronto, ON, Canada

e-mail: matteo.parotto@uhn.ca

Department of Anesthesia and Pain Management, Toronto General Hospital, EN 429 - 200 Elizabeth Street, Toronto, ON M5G 2C4, Canada

Interdepartmental Division of Critical Care Medicine, University of Toronto, Toronto, ON, Canada

F. Cavallin, MSc

Independent statistician, Solagna, Italy
2020. Participants reported details of airway management, personal health outcomes, personal protective equipment used, and personnel involved. Intubation reports predating enrolment were permitted. We present the Canadian data from this international registry and discuss their implications.

From 3 March to 7 August 2020, 54 HCWs (37 males and 17 females; median [interquartile range (IQR)] age 41 [37-48] years; majority anesthesiologists) from 37 Canadian hospitals registered at least one tracheal intubation in a COVID-19 patient and subsequently recorded their own COVID-19 infection status. Overall, 136 tracheal intubations in COVID-19 patients (44 confirmed and 92 suspected) were reported (median [IQR] intubations per participant, 2 [1-2]). The Table summarizes the details. Participants were the primary intubator in most procedures. Respiratory failure was the main indication for intubation and $75 \%$ were performed in the intensive care unit or emergency department. Rapid sequence induction was most commonly employed, a videolaryngoscope was the first-

G. L. Bryson, MD

Department of Anesthesiology and Pain Medicine, University of Ottawa, Ottawa, ON, Canada

Clinical Epidemiology Program, Ottawa Hospital Research Institute, Ottawa, Canada

K. J. Chin, MD

Department of Anesthesiology and Pain Medicine, University of Toronto, Toronto, ON, Canada

Department of Anesthesia and Pain Management, Toronto Western Hospital, Toronto, ON, Canada 
Table 1 Details of tracheal intubations in COVID-19 patients for Canadian participants in the intubateCOVID registry from 3 March to 7 August 2020

\begin{tabular}{|c|c|}
\hline Number of intubations & 136 \\
\hline \multicolumn{2}{|l|}{ Patient COVID-19 status } \\
\hline Confirmed & $44(32.4 \%)$ \\
\hline Suspected & $92(67.6 \%)$ \\
\hline \multicolumn{2}{|l|}{ Airway manager involvement } \\
\hline Intubator/laryngoscopist & $\begin{array}{l}125 \\
\quad(91.9 \%)\end{array}$ \\
\hline Assistant & $11(8.1 \%)$ \\
\hline \multicolumn{2}{|l|}{ Intubator/laryngoscopist } \\
\hline Anesthesiologist & $\begin{array}{l}127 \\
\quad(93.4 \%)\end{array}$ \\
\hline Intensive care physician & $6(4.4 \%)$ \\
\hline Others & $3(2.2 \%)$ \\
\hline \multicolumn{2}{|l|}{ Airway assistant } \\
\hline Anesthetic nurse & $37(27.2 \%)$ \\
\hline Other nurse & $22(16.2 \%)$ \\
\hline Anesthesiologist & $15(11.0 \%)$ \\
\hline Other doctor & $9(6.6 \%)$ \\
\hline Intensive care doctor & $5(3.7 \%)$ \\
\hline Other healthcare provider & $48(35.3 \%)$ \\
\hline \multicolumn{2}{|l|}{ Indication } \\
\hline Deteriorating respiratory failure & $80(58.8 \%)$ \\
\hline General anesthetic for surgery & $24(17.7 \%)$ \\
\hline Cardiac arrest & $16(11.8 \%)$ \\
\hline Airway protection for low Glasgow Coma Scale & $10(7.4 \%)$ \\
\hline Endotracheal tube exchange & $3(2.2 \%)$ \\
\hline Elective tracheostomy & $1(0.7 \%)$ \\
\hline Other ICU airway manipulation & $1(0.7 \%)$ \\
\hline Other indication & $1(0.7 \%)$ \\
\hline \multicolumn{2}{|l|}{ Location } \\
\hline ICU & $61(44.9 \%)$ \\
\hline Emergency department & $41(30.1 \%)$ \\
\hline Operating room & $24(17.6 \%)$ \\
\hline General ward & $5(3.7 \%)$ \\
\hline Other & $5(3.7 \%)$ \\
\hline Rapid sequence induction & $\begin{array}{l}107 \\
\quad(78.8 \%)\end{array}$ \\
\hline \multicolumn{2}{|l|}{ First attempt laryngoscopy device } \\
\hline Videolaryngoscope & $\begin{array}{l}124 \\
\quad(91.2 \%)\end{array}$ \\
\hline Direct laryngoscope & $8(5.8 \%)$ \\
\hline Flexible bronchoscope & $2(1.5 \%)$ \\
\hline Tracheostomy/front-of-neck access & $2(1.5 \%)$ \\
\hline Use of bag-mask ventilation & $19(14.0 \%)$ \\
\hline Use of supraglottic airway & $4(2.9 \%)$ \\
\hline \multicolumn{2}{|l|}{ Final airway management device } \\
\hline Endotracheal tube (oral) & $\begin{array}{l}132 \\
\quad(97.1 \%)\end{array}$ \\
\hline Emergency front-of-neck access & $2(1.5 \%)$ \\
\hline
\end{tabular}

Table 1 continued

\begin{tabular}{lc}
\hline Elective tracheostomy & $1(0.7 \%)$ \\
Supraglottic airway & $1(0.7 \%)$ \\
Number of attempts & \\
1 & 128 \\
& $(94.1 \%)$ \\
2 & $6(4.4 \%)$ \\
3 & $2(1.5 \%)$ \\
Personal protective equipment & \\
Gloves & 135 \\
& $(99.3 \%)$ \\
Eyewear/faceshield & 133 \\
& $(97.8 \%)$ \\
Gown & 132 \\
& $(97.1 \%)$ \\
Apron & $12(8.8 \%)$ \\
Hat & 129 \\
& $(94.9 \%)$ \\
FFP2/N95 (or equivalent) & 109 \\
FFP3/N99 (or equivalent) & $(80.1 \%)$ \\
Surgical mask & $19(14.0 \%)$ \\
Plastic drape/plastic intubation box & $17(12.5 \%)$ \\
PAPR & $10(7.4 \%)$ \\
Procedures where WHO personal protective & $5(3.7 \%)$ \\
equipment standards were not met* & $5(3.7 \%)$ \\
Median [IQR] & \\
Min-max & $3[3,4]$ \\
\hline & $2-12$ \\
\hline
\end{tabular}

*One participant did not use eyewear and a gown/apron; one participant did not use any mask/respirator; two participants did not use gown/apron; one participant did not use gloves.

COVID 19 = coronavirus disease; $\mathrm{ICU}$ = intensive care unit; IQR = interquartile range; FFP = filtering facepiece; PAPR = powered airpurifying respirator; WHO $=$ World Health Organization.

line device, and there was a high first-attempt success rate. Two emergency front-of-neck airways (eFONA) were reported (one in the resuscitation of a cardiac arrest, where eFONA was performed after two failed videolaryngoscopy attempts, and another where FONA was the first airway attempt in a patient with laryngeal trauma from a stab injury).

Laboratory-confirmed COVID-19 was reported in one HCW five days after the intubation (1/54 HCWs, $1.9 \%$; one HCW/136 intubations, 0.7\%). Two HCWs self-isolated because of symptoms (but subsequently tested negative for COVID-19) six and 23 days after the intubation, respectively (2/54 HCWs, 3.7\%; 2 HCWs/136 intubations, $1.5 \%$ ). Personal protective equipment (PPE) was widely used, but World Health Organization 
recommended standards ${ }^{3}$ were not met in five procedures (all occurring in March and April; reasons for these safety breaches could not be ascertained). The recommendation of minimizing the number of HCWs in the room to mitigate risk exposure ${ }^{4,5}$ was broadly followed (median [IQR] 3 [3-4]), but up to 10-12 individuals were present in two intubations (details of these events were not available).

Minimizing unnecessary HCW exposure remains an important focus and establishing dedicated airway response teams may help in this regard. Our findings should be interpreted within the limitations of a voluntary selfreported registry. The data undoubtedly represent only a small sample of COVID-19-related intubations performed in Canada, and a causal link between participation in airway management and subsequent COVID-19 infection cannot be ascertained. At the time of writing, Canada is into its second wave of COVID-19 infections, and data from continued participation in registries such as intubateCOVID will be valuable in guiding healthcare management policies.

Disclosures None.

Funding statement The intubateCOVID project received financial support from the Difficult Airway Society (UK), The American Society of Anesthesiologists, the International Anesthesia Research Society, and the Anesthesia Patient Safety Foundation. M. Parotto is supported by an Early Investigator Award from the Department of Anesthesiology and Pain Medicine, University of Toronto, and Toronto General Hospital.
Editorial responsibility This submission was handled by Dr. Hilary P. Grocott, Editor-in-Chief, Canadian Journal of Anesthesia.

\section{References}

1. Tran K, Cimon K, Severn M, Pessoa-Silva CL, Conly J. Aerosol generating procedures and risk of transmission of acute respiratory infections to healthcare workers: a systematic review. PLoS One 2012. https://doi.org/10.1371/journal.pone.0035797.

2. El-Boghdadly $K$, Wong DJ, Owen R, et al. Risks to healthcare workers following tracheal intubation of patients with COVID-19: a prospective international multicentre cohort study. Anaesthesia 2020; 75: 1437-47.

3. World Health Organization. Rational use of personal protective equipment for coronavirus disease (COVID-19) and considerations during severe shortages: interim guidance, 6 April 2020. Available from URL: https://apps.who.int/iris/handle/10665/331695 (accessed December 2020).

4. Resuscitation Council UK. Resuscitation Council UK statement on COVID-19 in relation to CPR and resuscitation in healthcare settings. Available from URL: https://www.resus.org.uk/covid-19resources/statements-covid-19-hospital-settings/resuscitationcouncil-uk-statement-covid. Published March 2020 (accessed December 2020).

5. Thiruvenkatarajan $V$, Wong DT, Kothandan H, et al. Airway management in the operating room and interventional suites in known or suspected COVID-19 adult patients: a practical review. Anesth Analg 2020; 131: 677-89.

Publisher's Note Springer Nature remains neutral with regard to jurisdictional claims in published maps and institutional affiliations. 